Health Informatics - An International Journal (HIIJ) Vol.4, No.3/4, November 2015

\title{
IMPACT OF HEALTH INFORMATICS TECHNOLOGY ON THE IMPLEMENTATION OF A MODIFIED EARLY WARNING SCORE (MEWS)
}

\author{
Sajeesh Kumar \\ Department of Health Informatics \& Information Management, University of Tennessee \\ Health Science Center, Memphis, TN, USA
}

\begin{abstract}
The Modified Early Warning System (MEWS) is based on a patient score that helps the medical team monitor patients to identify a patient that may be experiencing a sudden decline in care. This study consists of a detailed review of clinical data and patient outcomes to assess impact of technology and patient care. There are a total of thirteen hospitals included in this review. These facilities have implemented vitals capture and the MEWS scoring system.
\end{abstract}

\section{KEYWORDS}

Modified Early Warning System, electronic health record, Meaningful Use

\section{INTRODUCTION}

The adoption of Electronic Health Records has increased in recent years. As a result discrete data elements are more widely available which can be leveraged for secondary use. Clinical decision support and alert notification to clinicians are examples of such uses. The implementation of early warning systems can assist in identifying patients that may be at risk for decomposition or decline in clinical condition. Specifically, clarifications of availability in near real-time to facilitate the calculation of the Modified Early Warning Score (MEWS).

The Modified Early Warning System is based on a patient score that helps the medical team monitor patients to identify a patient that may be experiencing a sudden decline in care. Based on literature review the data elements and threshold vary slightly be essentially include the following: Respiratory Rate, Heart Rate, Systolic Blood Pressure, Consciousness/Alertness Level, Temperature and Urine Output.

The use of technology to aid in patient care and nursing workflow has evolved significantly over the last several years. In addition to the implementation of electronic health records, organizations are implementing electronic vital capture devices (capsules). This equipment is used to electronically transmit data from a device to the electronic health record (EHR). The patients' vitals are used in real-time to facilitate the calculation of the MEWS scores. The goal of this research is to evaluate the use of the medical devices in facility and assess the availability of data elements to calculate the MEWS score. This current work seeks to further explore the impact vitals capture and MEWS implementation on patient outcomes such as cardiac arrest, length of stay (LOS) and mortality.

DOI: $10.5121 /$ hiij.2015.4403 
This study consists of a detailed review of clinical data and patient outcomes to assess impact of technology and patient care. There are a total of thirteen hospitals included in this review. These facilities have implemented vitals capture and the MEWS scoring system. This population may be biased if they are considered early adopters of technology. Any conclusions would need to be interpreted with understanding of this study limitation.

\section{LITERATURE}

This literature search was conducted using electronic databases MEDLINE, PubMed, and Up To Date. The search terms included but not limited to: modified warning systems, modified early warning system, MEWS, MEWS Score, pediatric warning systems, PEWS, PEWS Score, PEWS and Sepsis. The advanced search filters were also used to limit those articles published from the year 1990 through the current year 2014. These techniques resulted in almost 800 possibly relevant articles. After manual review, 66 articles appeared relevant to thesis topic. A more detailed review of each abstract was conducted this resulted in 5 articles that provided additional background and 6 articles with original research.

FIGURE 1: Literature Search Flow Diagram

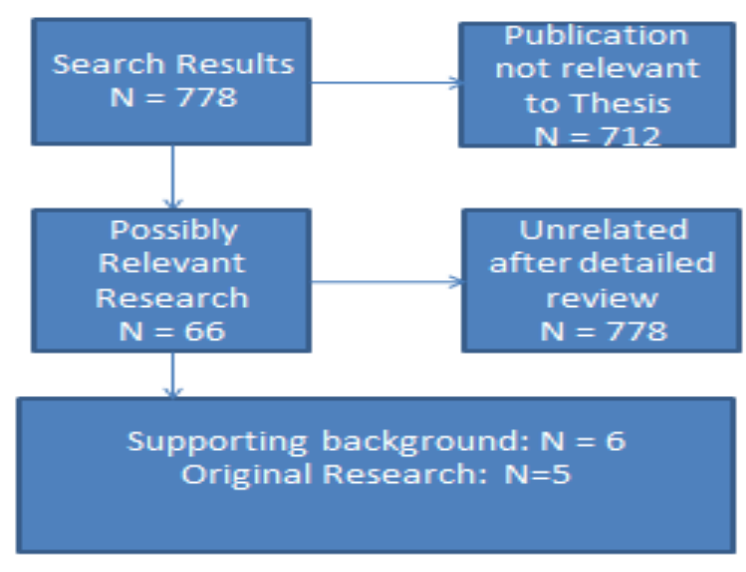

Modified Early Warning Systems (MEWS) attempt to identify deteriorating patients early so timely interventions can occur thus reducing serious adverse events (Hammond et al, 2012).

The studies were split based on patient age. One group consisted of two articles focused on the pediatric population and the Pediatric Early Warning System (PEWS) score. The other group consisted of three articles which were focused on the adult patient population and the MEWS score. The populations studied were in the following countries: United States, United Kingdom and Australia.

\section{Survey Methods and Variables}

The study methods varied across all articles that were reviewed. However, they all included a retrospective review. It is important to indicate that the scoring tools in both of the pediatric studies were generally similar. The tool from the Duncan 2012, article had a few additional evaluation criteria in each of the areas. Additionally, this tool included a color coding system. 
Health Informatics - An International Journal (HIIJ) Vol.4, No.3/4, November 2015

\begin{tabular}{|c|c|c|}
\hline Author(s), Year & Survey Methods & Variahles \& Results \\
\hline $\begin{array}{l}\text { Akre, M., Finkelstein, M., } \\
\text { Erickson, M., Liu, M., } \\
\text { Vanderbilt, L., \& Billman, } \\
\text { G. (2010) }\end{array}$ & 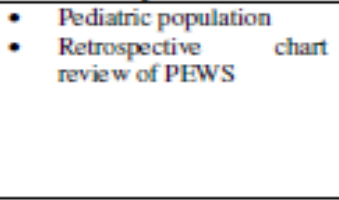 & $\begin{array}{l}\text { - PEWS score: behavior, } \\
\text { cardiovascular, respiratory; } \\
\text { adapted from } 2005 \\
\text { Pediatric Nursing Journal } \\
\text { PEWS can potentially } \\
\text { provide a forewarning time } \\
\text { greater than } 11 \text { hours }\end{array}$ \\
\hline $\begin{array}{l}\text { Duncan, K. D., McMullan, } \\
\text { C., \& Mills, B. M. (2012) }\end{array}$ & 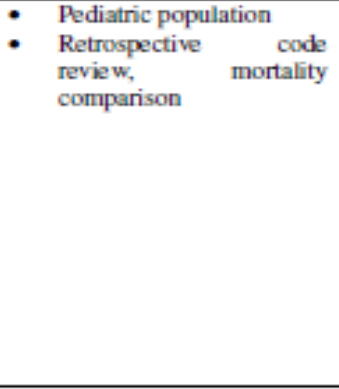 & $\begin{array}{l}\text { - PEWS score: behavior, } \\
\text { cardiovascular, respiratory; } \\
\text { adapted from the National } \\
\text { Institute for Children's } \\
\text { Health Care Quality } \\
\text { Conference (2007) } \\
\text { Expanded implementation } \\
\text { to adult population } \\
\text { Pediatric patients the } \\
\text { observed to expected } \\
\text { mortality and length of stay } \\
\text { was lower post } \\
\text { implementation of the } \\
\text { PEWS }\end{array}$ \\
\hline $\begin{array}{l}\text { Gardner-Thorpe J.,Love N., } \\
\text { Wrightson J., Walsh S., } \\
\text { Keeling N.(2006) }\end{array}$ & 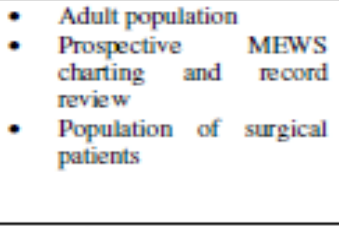 & $\begin{array}{l}\text { - Respiratory rate, heart rate, } \\
\text { systolic blood pressure, } \\
\text { urine output, emperature, } \\
\text { neurological assessment } \\
\text { - Call-out algorithm } \\
\text { - } 79 \% \text { of patients that trigged } \\
\text { the MEWS were managed } \\
\text { successfully }\end{array}$ \\
\hline $\begin{array}{l}\text { Hammond,N., Spooner, A., } \\
\text { Barnett, A., Corley, A., } \\
\text { Brown, P., Fraser, J. (2012) }\end{array}$ & $\begin{array}{l}\text { - Adult population } \\
\text { - Prospective before and } \\
\text { after MEWS charting } \\
\text { and education } \\
\text { intervention study } \\
\text { - November } 2009 \text { before } \\
\text { implementation } \\
\text { - February } 2010 \text { after } \\
\text { implementation }\end{array}$ & $\begin{array}{l}\text { - Blood pressure, heart rate, } \\
\text { temperature, oxygen } \\
\text { saturation, respiratory rate, } \\
\text { urine output } \\
\text { A fter the MEWS } \\
\text { implementation } 210 \% \\
\text { increase in full vital sign } \\
\text { documentation }\end{array}$ \\
\hline $\begin{array}{l}\text { Subbe, C.P., Kruger, M., } \\
\text { Rutherford, P. and Gemmel, } \\
\text { L. (2001) }\end{array}$ & $\begin{array}{l}\text { - } \quad \text { Adult population } \\
\text { All medical emergency } \\
\text { admissions during March } \\
2000\end{array}$ & $\begin{array}{l}\text { - Blood pressure, heart rate, } \\
\text { respiratory rate, } \\
\text { temperature, AVPU score } \\
\text { Outcome measures } \\
\text { include, death, intensive } \\
\text { care unit admission, high } \\
\text { dependency unit admission } \\
\text { or cardiac arrest }\end{array}$ \\
\hline
\end{tabular}

In the Sensitivity of the Pediatric Early Warning Score article, the researchers highlighted two prior studies that addressed the Pediatric Early Warning Score (PEWS) to unplanned transfers to a higher level of care. Additionally, the authors identified that this study "added" to the collective research. The team had a hypothesis that at least $80 \%$ of patients had a critical PEWS score preceding the event (code call/rapid response team notification). The study was conducted through a retrospective chart review of 186 cases/unique patients that had a rapid response team and/or code blue event. Based on the records identified, a nurse that specialized in critical care determined the PEWS for each patient at various intervals in the 24 hours prior to the event. Additional data was also collected to further aid the research. The study concluded that sensitivity of the PEWS was $85.5 \%$, defined as the patient having a critical score within 24 prior to the event. The team determined that the median time for the first critical PEWS event was 696 minutes (11 hours and 36 minutes). In the other article that addressed the pediatric population the authors focused on the experience of Stony Brook University Medical Center (SBUMC) and their journey with implementing an early warning system. The center started with the implementation of the Pediatric Early Warning Score (PEWS) in 2007. They provided detailed descriptions that presented an overview of the workflow and processes that should be taken based on the patient's score. They implemented a status board at each nursing station providing a quick view of the unit's general acuity level. The program has been 
expanded to the adult population and SBUMC has implemented the modified early warning system (MEWS). These tools continued to be refined and have been incorporated into the electronic health record. However, the facility has identified limitations with bedside documentation. As a result, there could be delays in the scoring and alerting of the patient's condition. Even with some of the limitations, the utilization of the warning system is another tool that staff can use to help patients that may be at risk for a decompensating condition (Duncan, et al 2012).

The other two articles focused on the adult population. In the third article by Gardner-Thorpe, J. et al (2006), the study included 334 elective and emergent surgical patients that were selected over a five month period. The team conducted prospective data collection on various elements (age, gender, American Society of Anesthesiologists (ASA) Physical Status Classification System surgical operation, length of stay) as the MEWS was calculated for each patient daily. In the data analysis the team selected a threshold of a MEWS greater than four or more. Of these patients, $75 \%$ had triggered the early warning system and went to critical care. They also completed detailed sensitivity and specificity testing to demonstrate how the MEWS could be leveraged as a predictor of admission to a critical care unit. In another, there was a review of the frequency of vital signs before and after the implementation of MEWS charting and staff education. The study evaluated 69 patients pre-implementation and 70 patients post-implementation. For the purpose of the study a full set of patient vitals included blood pressure, heart rate, temperature, oxygen saturation, respiratory rate and urine output. This study has very specific findings that indicated a $210 \%$ increase in overall frequency of vital sign documentation. This study was limited to the ICU population and was done within three months of the implementation of the MEWS (Hammond et al, 2012).

Modified Early Warning Score (MEWS) transforms this physiological data, and using weighted criteria, determines an aggregate score that may be used to categorize clinical deterioration and direct care. The score can be determined electronically or manually based on the processes of the individual facilities. The table below illustrates the scoring system. In 2001, Subbe et al. validated a Modified Early Warning Score (MEWS) that demonstrated a significant relationship between the score and transfers to the ICU or death. Additionally the study indicates that a clinical pathway or alerting system could be implemented to have clinical staff respond to those patients with high scores to respond with medical intervention. In this study, there is a bedside evaluation of the patient and calculation of the MEWS score with a screening tool to assist in the identification of patients that might be at risk. The score is comprised of five measures:

1. Blood pressure

2. Heart Rate

3. Temperature

4. Level of Consciousness or (AVPU)

5. Respiratory Rate

\begin{tabular}{|l|c|c|c|c|c|c|c|}
\hline \multicolumn{7}{|l|}{ Table 2: MEWS Scoring System } \\
\hline Components & 3 & 2 & 1 & 0 & 1 & 2 & 3 \\
\hline $\begin{array}{l}\text { Systolic Blood } \\
\text { Pressure (mmHg) }\end{array}$ & $<70$ & $71-$ & $81-$ & $101-$ & & $\geq 200$ & \\
\hline $\begin{array}{l}\text { Pulse Rate (HR) } \\
\text { (bpm) }\end{array}$ & & $<0$ & 100 & 199 & & & \\
\hline $\begin{array}{l}\text { Respiratory rate } \\
\text { (bpm) }\end{array}$ & & $<9$ & $41-$ & $51-100$ & $101-110$ & $111-129$ & $\geq 130$ \\
\hline Temperature (C) & & $<35$ & & $9-14$ & $15-20$ & $21-29$ & $\geq 30$ \\
\hline AVPU score & & & & Alert & Reacting & Reacting & Unresponsive \\
\hline
\end{tabular}


Health Informatics - An International Journal (HIIJ) Vol.4, No.3/4, November 2015

\begin{tabular}{|l|l|l|l|l|l|l|l|}
\hline & & & & & to Voice & to Pain & \\
\hline
\end{tabular}

This study concluded that the MEWS was a simple bedside tool that was administered by nursing staff. This tool helped to identify those patients that were at risk of deterioration and needed more acute clinical intervention.

All of the above studies independently concluded value in the implementation of MEWS and/or PEWS score. In general they found that there is a strong indicator of its potential to alert the care providers of the patient's clinical deterioration. Even with some of the limitations of the various studies, the researchers determined that the utilization of the warning system is another tool that staff can use to help patients that may be at risk for a decompensating condition. The authors concluded that the MEWS is an important part of a risk management strategy that is simple to implement, (Gardner-Thorpe J. et al 2006).

\section{METHOD}

This current study includes thirteen acute care facilities that have implemented the Vital Now technology and actively implemented the MEWS scoring system. This is a review patient level summary data and includes the evaluation of the availability of the key data elements to calculate the MEWS score. Additionally, the study also includes a review of a review of key outcome indicators. This includes the number of cardiac arrests, length of stay and mortality rate.

This data analysis is a retrospective data review from data collected in the calendar year 2013. The data has been extracted from the Enterprise Data Warehouse and specifically the clinical domain of vitals and internal outcomes reporting system. The facilities to be included in the evaluation would include the following, implementation of MEWS score, implementation of vitals capture and on the latest version of the HIS system. This would ensure that all required data elements had the potential to be present.

A select group of thirteen facilities have been selected for study. This will be referred to as the study cohort. Given the confidential and proprietary nature of the information, all patient identifiers have been removed and the facilities have been blinded for external review purposes.

\section{RESULTS}

The summary of the study results are described in the section below. Frist is the analysis of all facilities and their vital capture rates. The vitals capture metric includes several elements. The electronic vitals are defined as the total number of vitals obtained electronically and submitted through the neuron to the hospital information system (HIS). The manual vitals are defined as the total number of vitals entered manually into the HIS. The electronic vitals capture rate is a percentage as follows, (electronic/(manual + electronic))x 100.

Table 3: Vitals Capture 
Health Informatics - An International Journal (HIIJ) Vol.4, No.3/4, November 2015

\begin{tabular}{|c|c|c|c|c|c|c|c|c|c|}
\hline \multirow[b]{2}{*}{ Facility } & \multicolumn{3}{|c|}{6 Months } & \multicolumn{3}{|c|}{3 Months } & \multicolumn{3}{|c|}{ Last Month } \\
\hline & Electronic & Manual & Percentage & Electronic & Manual & Percentage & Electronic & Manual & Percentage \\
\hline A & 151689 & 16065 & 90 & 40925 & 2792 & 94 & 11074 & 624 & 95 \\
\hline$B$ & 160886 & 56412 & 74 & 78239 & 28655 & 73 & 6737 & 2000 & 77 \\
\hline C & 63963 & 31466 & 67 & 34931 & 17215 & 67 & 2976 & 1258 & 70 \\
\hline D & 143938 & 20666 & 87 & 84304 & 10949 & 89 & 6814 & 761 & 90 \\
\hline $\mathrm{E}$ & 123497 & 27834 & 82 & 64964 & 15175 & 81 & 4990 & 1181 & 81 \\
\hline $\mathrm{F}$ & 123289 & 27317 & 82 & 68923 & 11807 & 85 & 4985 & 550 & 90 \\
\hline G & 91692 & 18365 & 83 & 48256 & 8348 & 85 & 3520 & 756 & 82 \\
\hline $\mathrm{H}$ & 76286 & 12820 & 86 & 38200 & 6581 & 85 & 3335 & 587 & 85 \\
\hline 1 & 44829 & 9631 & 82 & 26211 & 5485 & 83 & 2240 & 332 & 87 \\
\hline $\mathrm{J}$ & 76442 & 8881 & 90 & 41530 & 4996 & 89 & 3655 & 387 & 90 \\
\hline $\mathrm{K}$ & 77434 & 10252 & 88 & 40617 & 5818 & 87 & 2739 & 362 & 88 \\
\hline $\mathrm{L}$ & 49362 & \begin{tabular}{l|}
3187 \\
\end{tabular} & 94 & 24697 & 1617 & 94 & 2240 & 106 & 95 \\
\hline$M$ & 113355 & 22831 & 83 & 62625 & 9545 & 87 & 5041 & 485 & 91 \\
\hline
\end{tabular}


In reviewing the data, Facility $\mathrm{C}$ has the lowest electronic capture rate with just $70 \%$ in the last month. Facilities A and L have the highest electronic capture rate. In the last month they both achieved 95\%. Upon review of the trend over the last six month, seven of the thirteen facilities improved their performance of the capture of vitals through the neuron to the HIS. This is a positive trend and would allow timely calculation of the MEWS score.

The next analysis is on the MEWS score calculation. The MEWS score metric includes several elements. The MEWS vitals are defined as the total number of vitals obtained electronically where the five elements are all present. This includes systolic blood pressure, heart rate, respiratory rate, body temperature and level of consciousness as measure by AVPU. Any vitals that are entered manually into the HIS are excluded from the numerator. The all vitals calculation is defined as the total number of vitals including both manual and electronic capture.

Table 4: MEWS Score Calculation

\begin{tabular}{|c|c|c|c|c|c|c|c|c|c|}
\hline & & 6 Months & & & 3 Months & & & _ast Month & \\
\hline Facility & \begin{tabular}{|l|} 
MEWS Vitals \\
\end{tabular} & \begin{tabular}{|l|} 
All Vitals \\
\end{tabular} & Percentage & \begin{tabular}{|l|} 
MEWS Vitals \\
\end{tabular} & All Vitals & \begin{tabular}{|l|} 
Percentage \\
\end{tabular} & MEWS Vitals & \begin{tabular}{|l|} 
All Vitals \\
\end{tabular} & Percentage \\
\hline $\mathrm{A}$ & 80930 & 105092 & 77 & 29782 & 37937 & 79 & 29782 & 37937 & 79 \\
\hline $\mathrm{B}$ & 77494 & 117448 & 66 & 33932 & 51868 & 65 & 15207 & 23729 & 64 \\
\hline C & 31145 & 48555 & 64 & 13511 & 21945 & 62 & 5870 & 9705 & 60 \\
\hline $\mathrm{D}$ & 90074 & 118001 & 76 & 43510 & 56989 & 76 & 18908 & 24632 & 77 \\
\hline $\mathrm{E}$ & 76568 & 91855 & 83 & 35541 & 42765 & 83 & 14537 & 17514 & 83 \\
\hline$F$ & 69377 & 87191 & 80 & 29306 & 38882 & 75 & 12375 & 16171 & 77 \\
\hline $\mathrm{G}$ & 46784 & 75284 & 62 & 22846 & 34005 & 67 & 10819 & 14755 & 73 \\
\hline $\mathrm{H}$ & 37008 & 53298 & 69 & 14914 & 21823 & 68 & 5865 & 8960 & 65 \\
\hline I & 31854 & 37818 & 84 & 15059 & 18010 & 84 & 6429 & 7901 & 81 \\
\hline $\mathrm{J}$ & 51996 & 63390 & 82 & 23944 & 29141 & 82 & 10124 & 12350 & 82 \\
\hline $\mathrm{K}$ & 38725 & 55141 & 70 & 15232 & 22318 & 68 & 6504 & 9777 & 67 \\
\hline$L$ & 32850 & 38043 & 86 & 15271 & \begin{tabular}{l|}
17441 \\
\end{tabular} & 88 & 6753 & 7845 & 86 \\
\hline $\mathrm{M}$ & 71597 & 80438 & 89 & 32499 & 36552 & 89 & 13527 & 15121 & 89 \\
\hline
\end{tabular}

FIGURE 3: MEWS Score Calculation Diagram

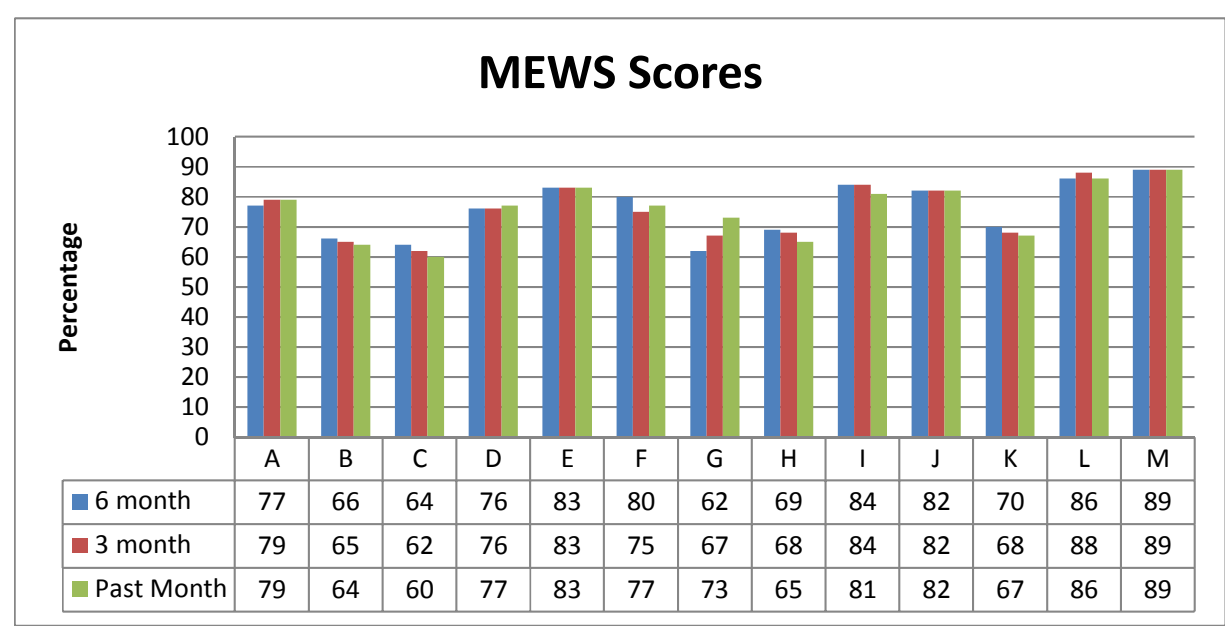


In reviewing the data, Facility $\mathrm{C}$ has the lowest MEWS Score calculation with just $60 \%$ in the last month. Facility A that had one of the highest electronic vital capture rate is only at $79 \%$ of the MEWS Score calculation. Facility M has the highest calculation with $89 \%$ over the last six months. It appears that more detailed analysis of the data would be important to understand which elements of MEWS score are not being captured electronically. This would be important to help improve the MEWS score calculation.

The next analysis of data is focused on outcomes in several categories. The first of which is looking at the incidence of cardiac arrest in the facility as defined by ICD-9-CM diagnosis code in either the primary or other diagnosis categories. This metric was defined as the total number of cardiac arrests divided by the total number of discharges $\mathrm{x} 100$ to calculate a percentage.

FIGURE 4: Percentage of Cardiac Arrests Diagram

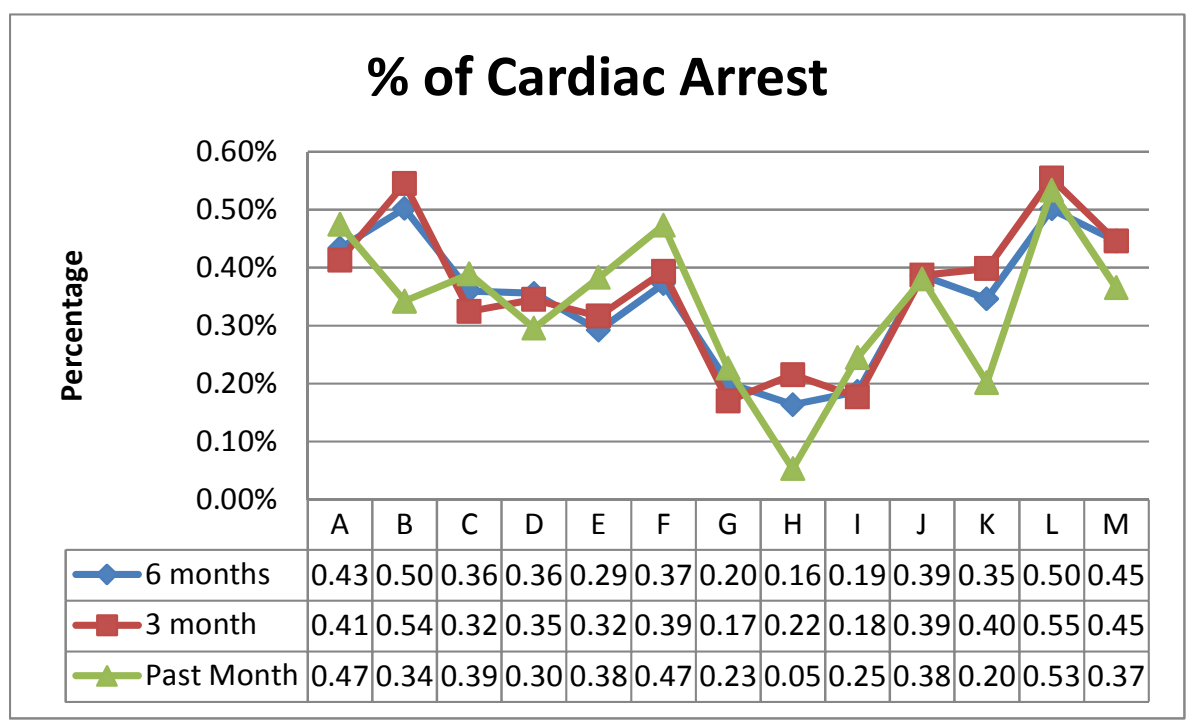

Upon review of the data all of the facilities had less than a $1 \%$ cardiac arrest rate. The percentages ranged from $.05 \%$ to $.55 \%$. Facility $\mathrm{H}$ has the lowest overall cardiac arrest rate. In general their vitals capture was about 85\% and their MEWS Score Calculation was 65-69\%.

In recent literature researcher has identified that there is the potential to leverage the MEWS score an early indication of patients that may be at risk for Sepsis. However, there does not appear any definitive correlation. Zavatti, L. et al (2010) concluded that there was a low sensitivity in the identification of patients with severe septic shock. However, the study was limited to the review of 51 patients in the study. The next data analysis was focused on patient outcomes (LOS and Mortality) for sepsis patients in the thirteen facilities. For both the length of stay and mortality there is a year over year comparison with 2013 as the current year and 2012 as the prior year. The first metric is length of stay. This is defined as the number of days during the patients stay. 
Health Informatics - An International Journal (HIIJ) Vol.4, No.3/4, November 2015

FIGURE 5: Sepsis Length of Stay Diagram

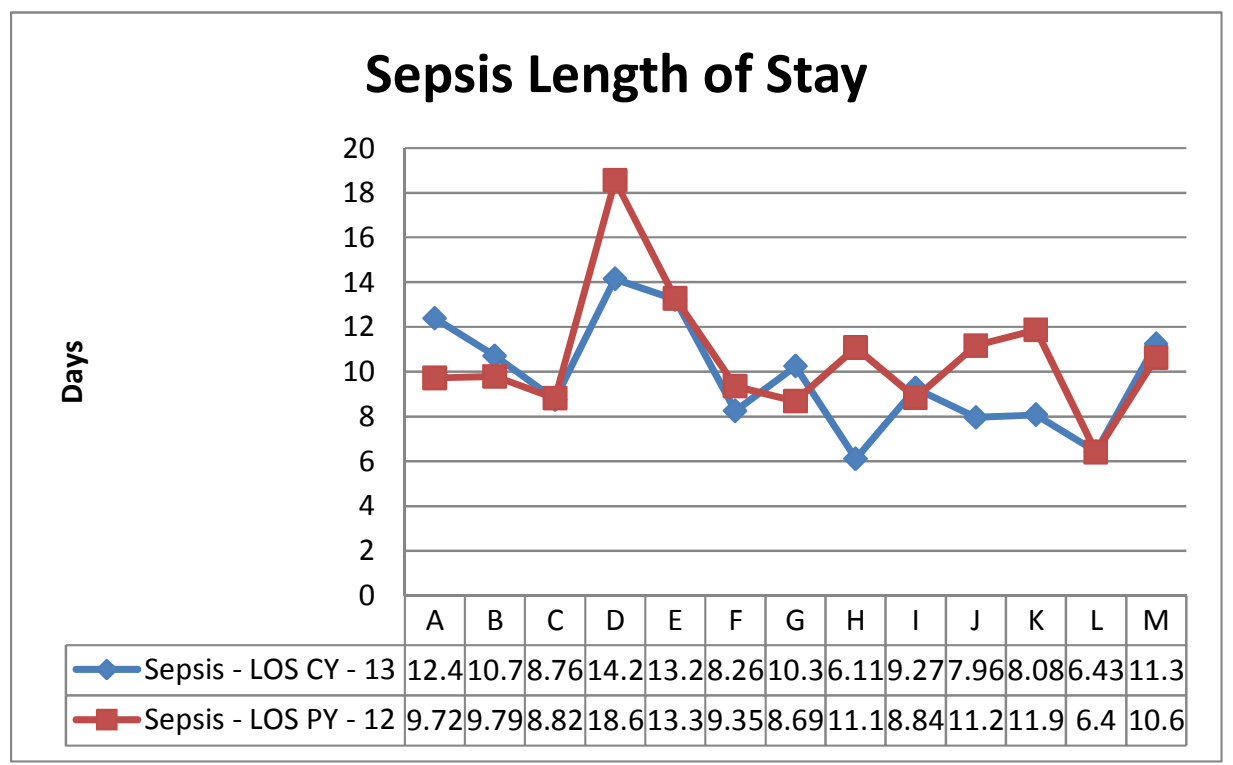

As noted in Figure 5, Sepsis Length of Stay Diagram, Facility D has the highest LOS in 2012 with 18.6. Facility D also had the highest LOS in 2013 with 14.2 days. However, this is a positive change of 4.4 days. Facility $\mathrm{H}$ had the lowest LOS in 2013 with just 6.11 days. This is a reduction of 5 days from the prior year. This is the same facility that had the lowest number of cardiac arrests.

The last analysis was the mortality rate. This metric is defined as the total number of patients in the reporting period and the total number of deaths. This analysis is also limited to just those patients with a diagnosis of sepsis.

FIGURE 6: Sepsis Mortality Rate Diagram

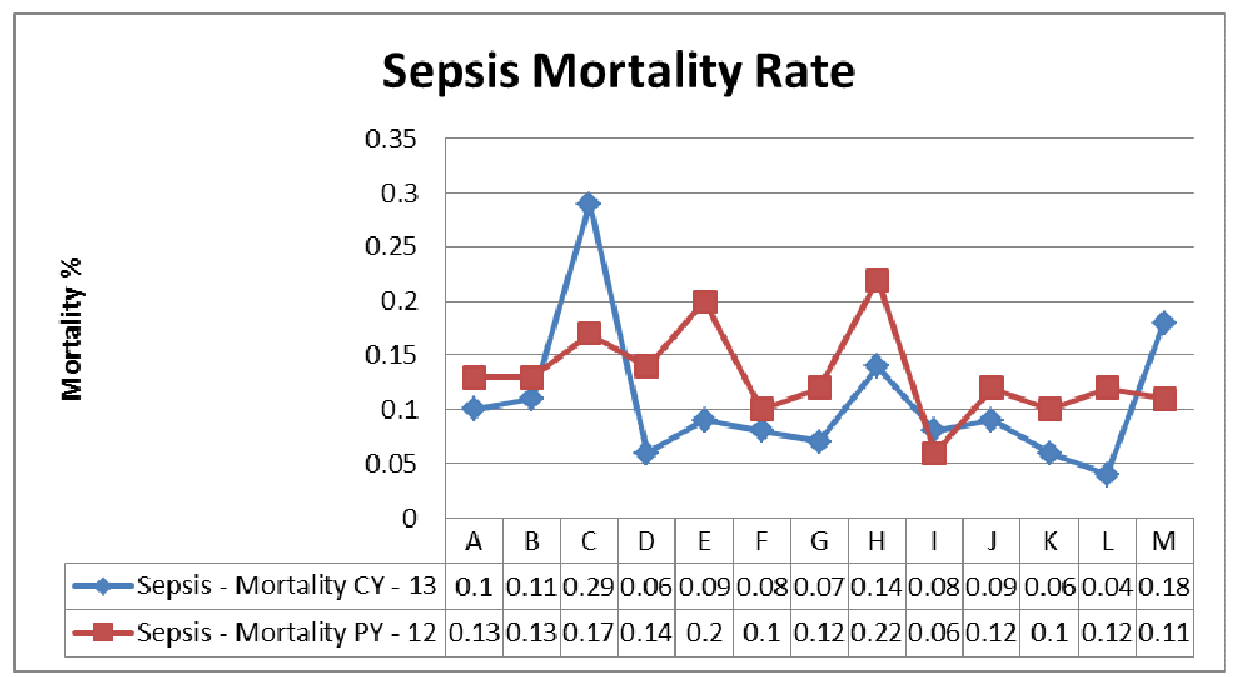

As noted in Figure 6, Sepsis Mortality Rate Diagram, 10 of the 13 Facility had a decrease in the Sepsis Mortality Rate from prior year. However, Facility $\mathrm{C}$ has the highest mortality 
Health Informatics - An International Journal (HIIJ) Vol.4, No.3/4, November 2015

rate in 2013 with $.29 \%$. Facility L has the lowest mortality rate with $.04 \%$. Facility D which had the highest LOS in 2013 with 14.2 days has the second lowest mortality rate with $.06 \%$.

\section{Conclusions}

In general there is data available electronically that can be leveraged for secondary use. Moreover, this data can be leveraged in near real-time to impact the care that is delivered to patients. The facilities in this study appear to have adopted the collection of vitals in an electronic method and compliance ranged from $95 \%-67 \%$ in the last six months. Additionally, the MEWS calculation when all five elements were present also appeared in $89 \%-60 \%$ of the cases. This provides an opportunity for improvement if the MEWS score were to be leveraged for alerting and monitoring. There may be an opportunity for more detailed analysis on each of the five components to determine if there is an educational opportunity or barrier to collecting all of the data required for the MEWS score calculation.

For the outcome measures there appeared to be a strong relationship in one facility where the low cardiac arrest rate also resulted in a low LOS for sepsis patients. There was also a notable finding in the facility with a higher length of stay and a lower mortality rate for 2013.

For future research, a recommendation would be to evaluate the patient outcomes prior to the implementation of MEWS at the facility. This might provide a more accurate impact analysis of MEWS and outcomes. Additionally study would be warranted to determine if MEWS could be an early predictor of sepsis.

\section{ACKNOWLEDGEMENTS}

The authors would like to thank the faculty at Department of Health Informatics and Information Management, University of Tennessee.

\section{REFERENCES}

[1] Akre, M., Finkelstein, M., Erickson, M., Liu, M., Vanderbilt, L., \& Billman, G. (2010). Sensitivity of the Pediatric Early Warning Score to identify patient deterioration. Pediatrics, 125(4), e763-e769.

[2] Duncan, K. D., McMullan, C., \& Mills, B. M. (2012). Early warning systems: The next level of rapid response. Nursing 2012, 42(2), 38-44.

[3] Gardner-Thorpe J., Love N., Wrightson J., Walsh S., Keeling N. The value of Modified Early Warning Score (MEWS) in surgical outpatients: a prospective observational study. Annals the Royal College of Surgeons of England. 2006;88(6):571-575.

[4] Gosfield, A. G., \& Reinertsen, J. L. (2005). The 100,000 lives campaign: crystallizing standards of care for Hospitals. Health Affairs, 24(6), 1560-1570.

[5] Hammond, N., Spooner, A., Barnett, A., Corley, A., Brown, P., Fraser, J. (2013). The effect of implementing a modified early warning scoring (MEWS) system on the adequacy of vital sign documentation. Australian Critical Care, 26 (2013) 18-22.

[6] Montagnolo, A. J. (2012). The Future of Connectivity. Trustee: The Journal for Hospital Governing Boards, 65(11), 25-26.

[7] Murphy K., Packer C., Stevens A., Simpson S., Hailey D., Robert G., Chan, L. (2007). Effective early warning systems for new and emerging health technologies: Developing an evaluation framework and an assessment of current systems. International Journal of Technology Assessment in Health Care, 23(3), 324-330.

[8] Subbe, C.P., Kruger, M., Rutherford, P. and Gemmel, L. (2001). Validation of an Early Warning Score in Medical Admissions. QJM 94:521-526 
Health Informatics - An International Journal (HIIJ) Vol.4, No.3/4, November 2015

[9] Winters, B. D., Pham, J. C., Hunt, E. A., Guallar, E., Berenholtz, S., \& Pronovost, P. J. (2007). Rapid response systems: A systematic review. Critical Care Medicine, 35(5), 1238-1243.

[10] Zavatti, L., Barbieri, E., Amateis, E., \& Girardis, M. Rapid response Modified Early Warning Score and identification of patients with severe sepsis. Critical Care. 2010; 14(Suppl 1)254.

\section{AUTHOR}

Sajeesh Kumar, PhD., is Executive Director- Institute for Health Outcomes and Policy, Chair-Health Outcomes and Policy Research PhD program and Associate Professor, Department of Health Informatics \& Information Management, University of Tennessee-Memphis. Dr. Kumar's research focuses on design and development of public health informatics, telemedicine technology, health education technologies and health informatics technology evaluation. Dr. Kumar holds an impressive record of competitive research funding and research awards.

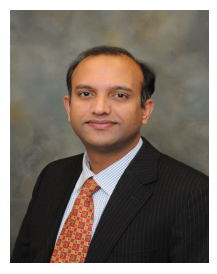

